\title{
An evaluation of iced bridge hanger vibrations through wind tunnel testing and quasi- steady theory
}

\author{
Gjelstrup, Henrik; Georgakis, Christos T.; Larsen, A.
}

Published in:

Wind \& Structures

Publication date:

2012

Document Version

Publisher's PDF, also known as Version of record

Link back to DTU Orbit

Citation (APA):

Gjelstrup, H., Georgakis, C. T., \& Larsen, A. (2012). An evaluation of iced bridge hanger vibrations through wind tunnel testing and quasi-steady theory. Wind \& Structures, 15(5), 385-407.

\section{General rights}

Copyright and moral rights for the publications made accessible in the public portal are retained by the authors and/or other copyright owners and it is a condition of accessing publications that users recognise and abide by the legal requirements associated with these rights.

- Users may download and print one copy of any publication from the public portal for the purpose of private study or research.

- You may not further distribute the material or use it for any profit-making activity or commercial gain

- You may freely distribute the URL identifying the publication in the public portal

If you believe that this document breaches copyright please contact us providing details, and we will remove access to the work immediately and investigate your claim. 


\title{
An evaluation of iced bridge hanger vibrations through wind tunnel testing and quasi-steady theory
}

\author{
H. Gjelstrup*1,2 ${ }^{*}$ C.T. Georgakis ${ }^{2}$ and A. Larsen ${ }^{1}$ \\ ${ }^{1}$ COWI A/S, Parallelvej 2, 2800 Kgs. Lyngby, Denmark \\ ${ }^{2}$ Department of Civil Engineering, Technical University of Denmark, Building 118, Brovej, \\ 2800 Kgs. Lyngby, Denmark \\ (Received November 5, 2010, Revised October 10, 2011, Accepted October 14, 2011)
}

\begin{abstract}
Bridge hanger vibrations have been reported under icy conditions. In this paper, the results from a series of static and dynamic wind tunnel tests on a circular cylinder representing a bridge hanger with simulated thin ice accretions are presented. The experiments focus on ice accretions produced for wind perpendicular to the cylinder at velocities below $30 \mathrm{~m} / \mathrm{s}$ and for temperatures between $-5^{\circ} \mathrm{C}$ and $1^{\circ} \mathrm{C}$. Aerodynamic drag, lift and moment coefficients are obtained from the static tests, whilst mean and fluctuating responses are obtained from the dynamic tests. The influence of varying surface roughness is also examined. The static force coefficients are used to predict parameter regions where aerodynamic instability of the iced bridge hanger might be expected to occur, through use of an adapted theoretical 3DOF quasi-steady galloping instability model, which accounts for sectional axial rotation. A comparison between the 3-DOF model and the instabilities found through two degree-of-freedom (2-DOF) dynamic tests is presented. It is shown that, although there is good agreement between the instabilities found through use of the quasi-steady theory and the dynamic tests, discrepancies exist-indicating the possible inability of quasi-steady theory to fully predict these vibrational instabilities.
\end{abstract}

Keywords: circular cylinder; bridge hangers; ice accretion; wind tunnel tests; aerodynamic instability; low temperatures; quasi-steady aerodynamics

\section{Introduction}

Several recently observed vibrations of bridge hangers have been attributed to the formation of thin ice on the outer surface of the hanger (Gjelstrup et al. 2007). Although, this is not necessarily a new phenomenon, little research has been undertaken on the effects of ice on the vibrational stability of cables, or other circular sections, for wind velocities below $30 \mathrm{~m} / \mathrm{s}$ and temperatures aboveows $-5^{\circ} \mathrm{C}$ (Lozki et al. 1983a, Lozowski et al. 1983b, Hansman et al. 1993, Anderson et al. 1998).

There are two traditional industries for which ice accretion of cylinders is of importance; the telecommunication and power line industry, and the aerospace industry. For the aerospace industry, temperatures of $-5^{\circ} \mathrm{C}$ to $-1^{\circ} \mathrm{C}$ and wind velocities lower than $30 \mathrm{~m} / \mathrm{s}$ are of little or no interest. For the telecommunication and power line industry, cables are usually of very small diameter.

\footnotetext{
* Corresponding author, Senior Consultant, E-mail: hegj@cowi.dk
} 
Furthermore, even though several studies involving real and simulated ice accretions on circular power lines have been reported(Nigol and Clarke 1974, Hack 1981, Nigol and Buchan 1981, Nigol 1981, Jamaleddine et al. 1993, McComber and Paradis 1995, Chabart and Lilien 1998, Gurung et al. 2002, Phuc 2005, Shimizu 2005, Kudzys 2006, Fo-chi et al. 2009, Dalle and Admirat 2010, Wang et al. 2010), the meteorological conditions associated with these cases differ from the situations in which large bridge cable vibrations have been reported.

To compensate for the lack of experimental data on the ice accretion of circular cylinders, under the aforementioned meteorological conditions of interest, a series of cylinder icing tests was undertaken at the NRC Institute for Aerospace Research, Altitude Icing Wind Tunnel Facility (AIWT), in Ottawa, Canada (Gjelstrup and Georgakis 2009, Koss et al. 2012). Several of the accreted ice shapes found from this research, together with one previously reported by Lozowski et al. (1983b), were reproduced employing a rapid prototyping technique and used for both the static and dynamic wind tunnel tests on an example cylinder. The static tests provided force coefficients that were used for the prediction of regions of vertical aerodynamic instability, by applying an adapted theoretical 3DOF quasi-steady galloping instability model proposed by Gjelstrup and Georgakis (2011), in which the along-flow degree-of-freedom was constrained. The dynamic tests were used to experimentally determine regions of aerodynamic instability, noting that the dynamic wind-tunnel rig was only capable of movement in two degrees-of-freedom, namely allowing for cross-flow displacements and axial torsion. For all of the tests, the wind flow was perpendicular to the cylinder.

The results from both the static and the dynamic tests, together with a comparison between the theoretically determined regions of aerodynamic instability and those determined experimentally, are presented herewith.

\section{Ice shapes considered for testing}

Several shapes of ice accretion were initially considered for testing. Four ice shapes, either as reported in literature by Lozowski et al. (1983b) or as determined by a series of tests presented in Gjelstrup and Georgakis (2009) and Koss et al. (2012) were finally chosen. These were based either on their resemblance to previously witnessed bridge hanger ice shapes that might have led to associated cable vibrations or those that are most likely to form under the most prevalent meteorological conditions. The variation in ice shape is predominantly due to five parameters, the liquid water content (LWC) of the air, the mean wind velocity $(U)$, the external temperature (Temp), the accretion time (Time) and the diameter $(D)$ of the cylinder. The variation on these parameters for each shape is provided in Table 1 and a photo of ice shape II, as obtained during wind tunnel tests, is shown in Fig. 1.

The cylinders tested in the wind tunnel were $960 \mathrm{~mm}$ long leaving a gap of $20 \mathrm{~mm}$ between the cylinder and the wind tunnel vertical walls. The ends of the cylinder were closed with metal fittings, sealing the cylinder at both ends. No endplates were used. Note that for all the tests, the base cylindrical cross section was $D_{b}=70 \mathrm{~mm}$ in diameter. All the simulated ices shapes used in the wind tunnel experiments can be seen in Fig. 2, where shape I is reported by Lozowski et al. (1983b) and shapes II and III originating from the test series reported by Gjelstrup and Georgakis (2009) and Koss et al. (2012). Finally simulated ice shape IV is defined below in section 3.

Ice shapes II and III were documented by melting a thin channel of ice (Fig. 1), to which a piece of cardboard was placed perpendicular to the cylinder, whereupon the ice surface was traced by pencil. 
An evaluation of iced bridge hanger vibrations through wind tunnel testing and quasi-steady theory 387

Table 1 Characteristics for ice shapes I-IV

\begin{tabular}{ccccccc}
\hline \hline $\begin{array}{c}\text { ice } \\
\text { shape }\end{array}$ & $\begin{array}{c}\text { LWC } \\
{\left[\mathrm{g} / \mathrm{m}^{3}\right]}\end{array}$ & $\begin{array}{c}U \\
{[\mathrm{~m} / \mathrm{s}]}\end{array}$ & $\begin{array}{c}\text { Temp } \\
{\left[{ }^{\circ} \mathrm{C}\right]}\end{array}$ & $\begin{array}{c}\text { Time } \\
{[\mathrm{min}]}\end{array}$ & $\begin{array}{c}\text { mean ice thickness } \\
{[\% \text { of diameter }]}\end{array}$ & $\begin{array}{c}\text { ice thickness at the stagnation point } \\
{[\% \text { of diameter }]}\end{array}$ \\
\hline I & 0.4 & 30 & -15 & 5 & 6.2 & 10.0 \\
II & 0.4 & 20 & -2 & 30 & 1.4 & 1.6 \\
III & 0.4 & 10 & -1 & 30 & 1.4 & 1.5 \\
IV & $\begin{array}{c}\text { cylinder with simulated ice: } \\
\text { 2 mm thick at the stagnation } \\
\text { point }\end{array}$ & 2.3 & 2.9 \\
\hline
\end{tabular}
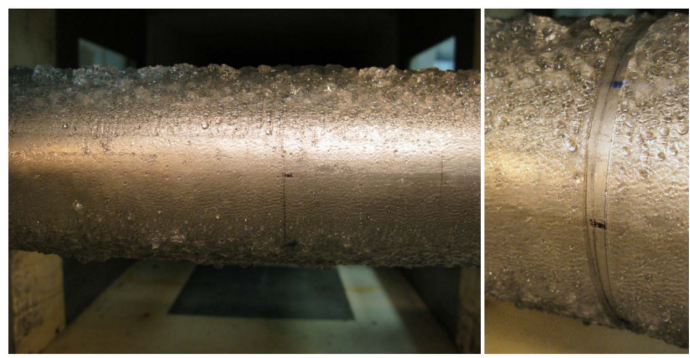

Fig. 1 Photo of ice shape II obtained during a wind tunnel test (left) and melted channel of ice for tracing the ice shape (right)
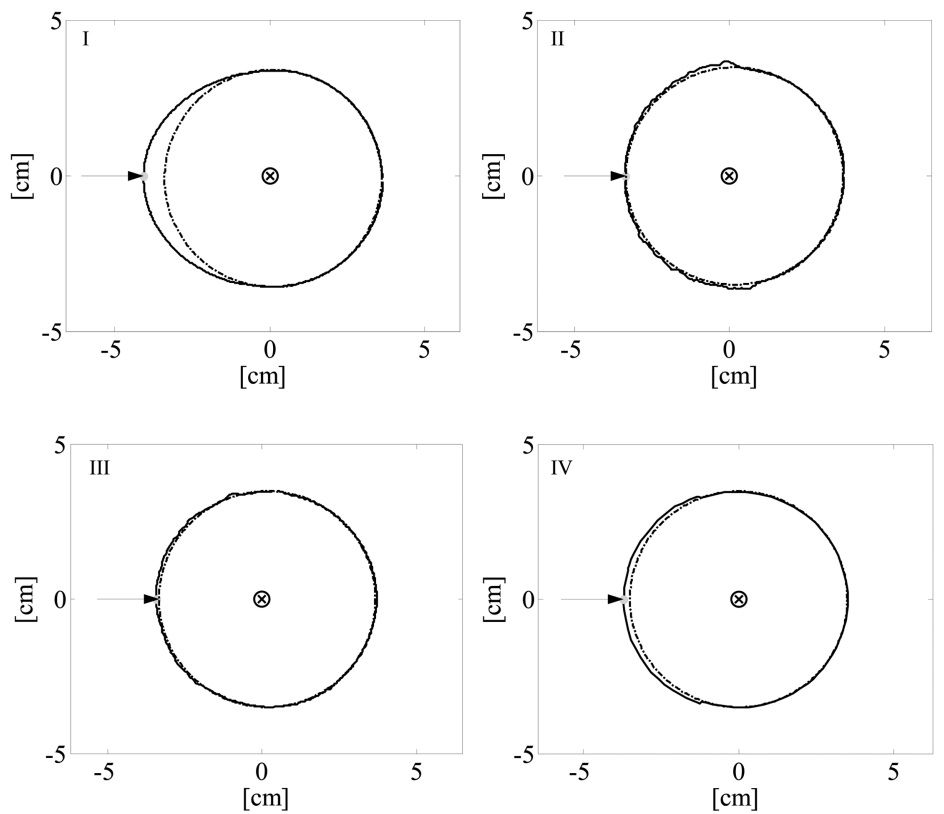

Fig. 2 Ice accretion shapes according to icing conditions presented in Table 1. $\otimes$ indicates the center of the cylinder and " $\rightarrow$ " indicates the stagnation point of the section from which the $0^{\circ}$ angle is defined. The positive change in wind angle-of-attack is counterclockwise. The dotted line illustrates the cylinder boundary behind the ice accretion. In all cases, the cylindrical section has a diameter of $70 \mathrm{~mm}$. 


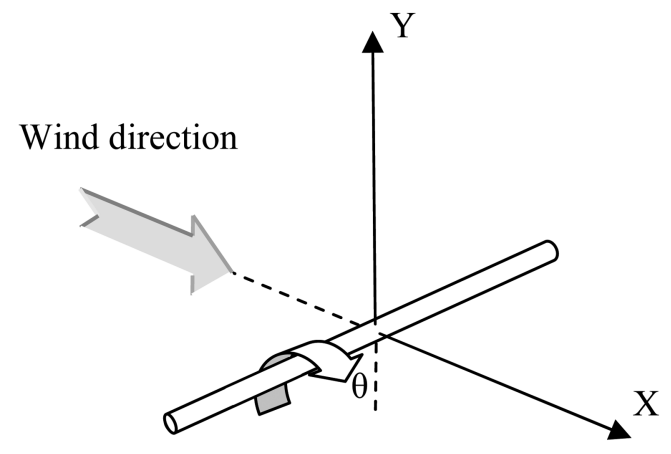

Fig. 3. Sign convention and model coordinate system

The coordinate system and sign convention used for all the experiments performed in the wind tunnel is presented in Fig. 3.

\section{Simulation of ice accretion}

For lack of availability of a specially designed climatic wind tunnel, simulated, and not real ice, was used for the static and dynamic wind-tunnel tests described herewith. Consequently, ice accretion shapes I-I V was reproduced using a non-melting material and a rapid-prototyping (3-D printing) technique. The accretion was printed as additional pieces that could be glued on to the base cylinder longitudinally. The simulated ice consists of five printed segments, each with a length of $192 \mathrm{~mm}$. The printing leads to a cross-sectionally consistant ice shape, but with inevitable print lines (striations), which, due to the printing direction, were perpendicular to the length axis of the model, i.e., parallel to the direction of the flow (see Fig. 4). These printing lines are a result of the printing process, which involves continual adding of a small layer of material on top of the previous layer. This is done in the model axis direction, resulting in the printing lines that can be seen in Fig. 4.

The striations leave a relatively rough surface that was not explicitly measured using roughness measurement equipment, but that is visually and texturally equivalent to an ISO/FEPA grit designation of P150 or slightly higher, (ISO 6344-2:1998). The surface roughness was considered beneficial, as it is known to shift the critical Reynolds number region to lower wind velocities

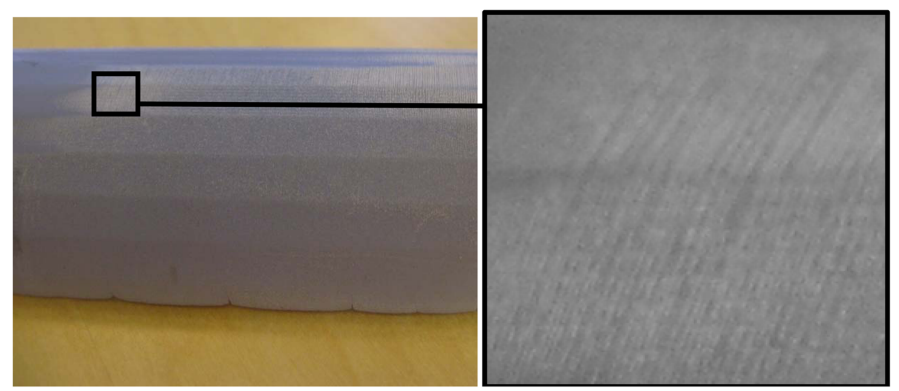

Fig. 4 Surface texture of rapid prototyping on a test print: original surface (left) and surface treated with sand paper to visualize the printing lines (right) 


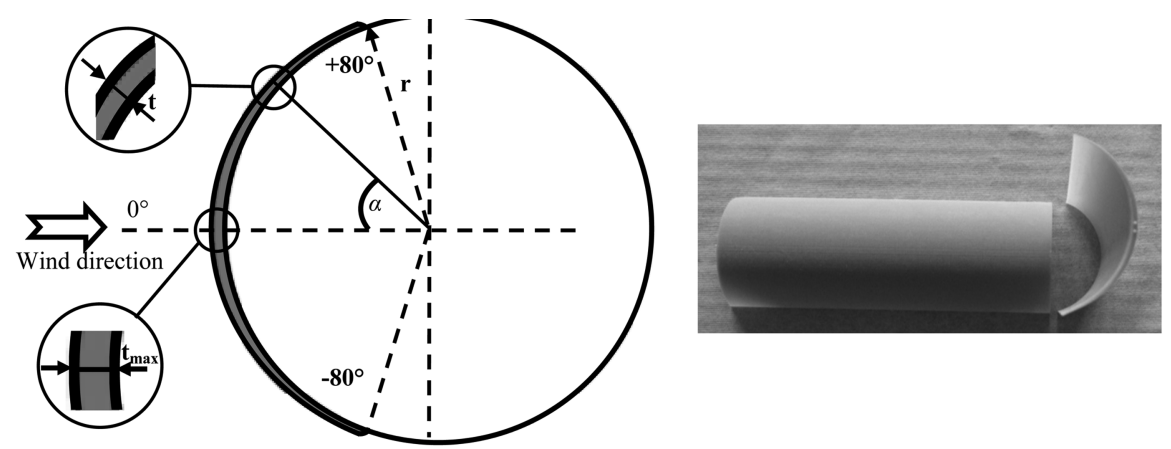

Fig. 5 Cross-section of model with ice (left) and simulated ice strip produced by rapid prototyping (right)

(ESDU 1986), allowing for the evaluation of the cylinder performance beyond the critical Reynolds number range. Furthermore, at least two distinct levels of roughness could be tested by treating the surface with different layers of varnish in order to obtain a smoother surface. For the experiments presented in the present paper, "rough" model surface refers to the originally manufactured surface, whilst "smooth" refers to the model surface that has been treated with four layers of varnish.

A photograph of the simulated ice accretion using rapid-prototyping is shown in Fig. 5 (right). The specific accretion is based on a simulated ice shape IV and has a mid-point (stagnation point) thickness of $2 \mathrm{~mm}$. For the specific shape, the thickness of the prototyped ice accretion zeroes at $\pm 80^{\circ}$ from the stagnation point. The ice thickness, $t$, as a function of angle from stagnation point can be expressed as

$$
t=-r+t_{\max } * \cos (\alpha)+\sqrt{\left(-t_{\max }^{2}+r^{2}+t_{\max }^{2} * \cos (\alpha)\right)}
$$

where, $r$ is the base cylinder radius, $t_{\max }$ is the ice stagnation thickness and $\alpha$ is the angle. The definition of the variables in Eq. (1) can also be found in Fig. 5 (left).

\section{Testing facility and instrumentation}

The experiments on the cylinders with simulated ice accretion were performed at the Closed Circuit Wind Tunnel (CCWT) facility at FORCE Technology, Lyngby, Denmark. The CCWT has a test section with a height of $0.70 \mathrm{~m}$ and a width of $1.00 \mathrm{~m}$. In the configuration used, the wind tunnel has a maximum wind velocity of approximately $60 \mathrm{~m} / \mathrm{s}$ for smooth flow, i.e., with a turbulence intensity of $I_{u} \quad 1 \%$. The maximum wind velocity drops to approximately $35 \mathrm{~m} / \mathrm{s}$ for turbulent flow, i.e., an along-wind turbulence intensity of approximately $I_{u}=6 \%-7 \%$.

In order to produce turbulent flow, a grid (Fig. 6) was placed in the wind tunnel at a distance of $0.84 \mathrm{~m}$ upstream of the models, as indicated in Fig. 7. The dimensions of the turbulence grid can be seen in Fig. 6, where $A$ and $B$ is the height and width of the square hole in the grid and $C$ is the width of the wooden elements comprising the grid.

The instrumentation used for the experiments can be split in to two groups centred around the type of test rig used. The wind velocity was measured with a pitot tube, which was located in the middle of the test chamber's cross-section and placed $0.5 \mathrm{~m}$ upstream of the tested models.

The section model was suspended between two 3 -DOF force gauges with a 12 bit $A / D$ resolution, 

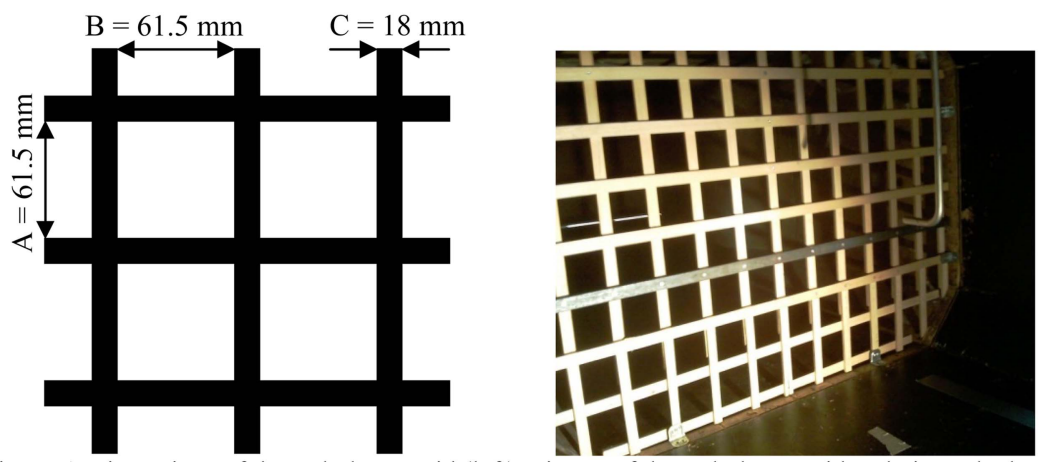

Fig. 6 Dimensions of the turbulence grid (left), Picture of the turbulence grid and pitot tube location (right)

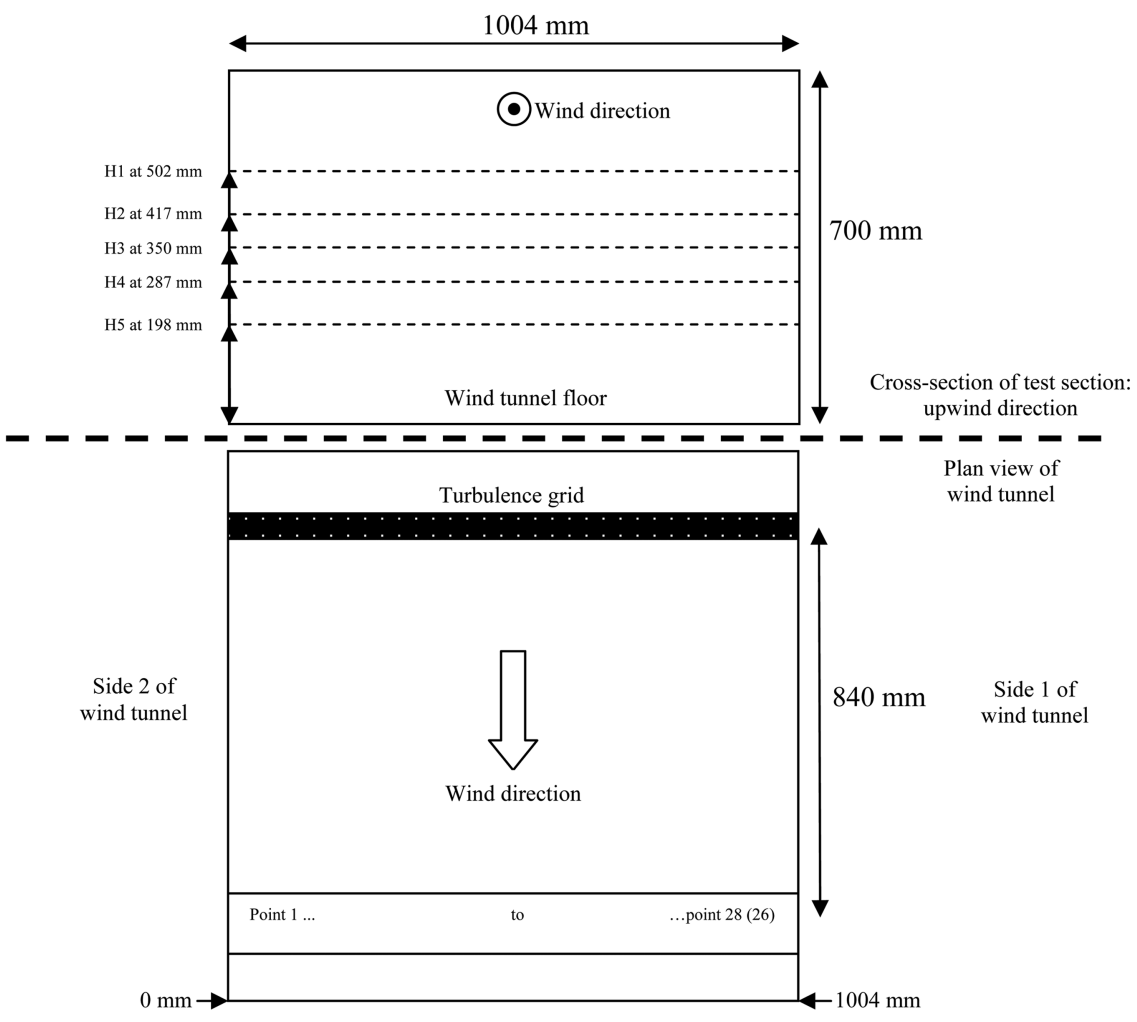

Fig. 7. Cross-section (top) and plan view (bottom) of the wind tunnel test section showing the vertical and horizontal positions for the wind-profile measurements

Force was measured about the cylinder axis (moment) and along the two orthogonal directions, $x$ and $y$.

The dynamic rig consists primarily of 4 springs, which allow the simulation of the vertical and torsional oscillations of a section model. Model vibration frequencies are adjusted by varying the spring length, and the spring spacing. Adjustment of model mass and mass moment of inertia is achieved through the addition or subtraction of mass to the dynamic test rig arms.

The displacements and rotations of the section model were measured using four optical 
displacement sensors (ODSs) and four accelerometers were used for backup measurements. The ODSs have a measuring range of $\max \pm 20 \mathrm{~mm}$ about a centered position with a resolution of $0.02 \mathrm{~mm}$.

\section{Wind profile measurements}

Due to potential flow asymmetry and variable wall friction that wind tunnels often exhibit, it was deemed necessary to map the wind profile of the wind tunnel in the velocity range of the planned experiments. The map of the wind profile was generated at five different heights in order to have a detailed picture of the wind velocity profile that either a static or a dynamic model would be subjected too. The measured wind velocity profiles are used when calculating the aerodynamic drag, lift and moment coefficients, so that

$$
\begin{aligned}
C_{D} & =\sum_{i=1}^{n} \frac{F_{x}}{1 / 2 \rho U^{2} D}\left(\frac{S_{i}}{L}\right) \\
C_{L} & =\sum_{i=1}^{n} \frac{F_{y}}{1 / 2 \rho U^{2} D^{2}}\left(\frac{S_{i}}{L}\right) \\
C_{M} & =\sum_{i=1}^{n} \frac{F_{\theta}}{1 / 2 \rho U^{2} D^{2}}\left(\frac{S_{i}}{L}\right)
\end{aligned}
$$

where $F_{x}, F_{y}$ and $F_{\theta}$ are the aerodynamic forces measured in the $\mathrm{x}, \mathrm{y}$ and $\theta$ directions respectively. $\rho$ and $D$ are the density of air and the diameter of the cylinder without ice, respectively. $n$ represents a sequential position along the width of the test section and the axis of the model. The numbering is from 1-28 for smooth flow and 1-26 for turbulent flow. $S_{i}$ is a section length of the model, which is defined by the length between the midpoint of the position of the wind profile point and $P_{i-1}$ and $P_{i}$ wind profile point $P_{i}$ and $P_{i+1}$, which can be calculated as $S_{i}=\frac{1}{2}\left(P_{i+1}+2 P_{i}+3 P_{i-1}\right)$, where the boundaries at $i=1$ and $i=n(28)$ or $n(26)$ are given by $S_{i}=P_{1}+\frac{P_{2}}{2}$ and $S_{n}=\frac{1}{2}\left(L-3 P_{n-1}+2 P_{n}\right) . L$ is the

total length of the section model being tested. $U=U_{E}\left(\frac{U_{i}}{U_{p}}\right)$ is the corrected mean wind velocity for section length $S_{i}$ for the tested model, where $U_{i}$ is the wind velocity for point $i$ in the wind velocity profile and $U_{p}$ is the wind velocity obtain from the pitot tube in the wind velocity profile test and finally $U_{E}$ is the wind velocity obtain from the pitot tube when undertaking the section model experiments.

\subsection{Position of wind profiles}

As previously mentioned, five horizontal profiles for each wind velocity were measured along the height of wind tunnel test section. The five different heights for the velocity profiles are named H1 to H5 (Fig. 7). 


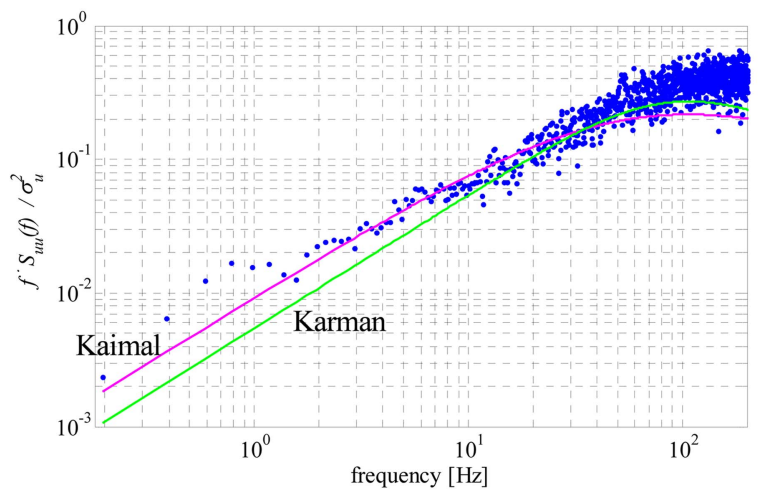

Fig. 8 Comparison of Kaimal and Karman spectrum to that obtained from turbulent flow with a wind velocity of $30 \mathrm{~m} / \mathrm{s}$.

Table 2 Wind velocities at which the profile was measured

\begin{tabular}{cccccccc}
\hline \hline flow condition & \multicolumn{7}{c}{ wind velocities $-[\mathrm{m} / \mathrm{s}]$} \\
\hline smooth $\left(I_{u} 1 \%\right)$ & 20 & 25 & 30 & 35 & 40 & 50 & 60 \\
turbulent $\left(I_{u}=6 \%-7 \%\right)$ & 20 & 25 & 30 & 35 & - & - & - \\
\hline
\end{tabular}

Measurements were taken for all measured points at 7 distinct wind velocities for smooth flow and 4 distinct wind velocities for turbulent flow. This was done to document any potential Reynolds number effects on the wind profile. Table 2 lists the wind velocities used for the profile measurements. The position of each measurement point along the width of the test section is listed in Table A1 of Appendix A for both smooth and turbulent flow profiles. Note that zero position starts at "Side 2" of the wind tunnel (see Fig. 7). Plots of a single set of wind velocity profiles for smooth flow and turbulent flow can found in Appendix A.

By examining the plots, it can be seen that the velocity profiles for smooth flow are relatively symmetric across the width of the wind tunnel for lower wind velocities. Contrary to the horizontal velocity profiles, it can be seen that the vertical profiles for turbulent flow vary significantly over the height, which might be attributable to the location of the grid bars.

Fig. 8 shows the normalized Kaimal and Karman wind spectra, plotted against the wind spectrum found from wind tunnel measurements obtained under turbulent flow and a wind velocity of $30 \mathrm{~m} / \mathrm{s}$, where $f^{*} S_{u u}(f) / \sigma_{u}^{2}$ is the normalized spectrum for the along wind direction. $f$ is the frequency, $S_{u u}(f)$ is the spectrum in the along wind direction and $\sigma_{u}^{2}$ variants in the along wind direction. Table 3 provides the integral length scale, $L_{u x}$, for all tested turbulent wind velocities.

Table 3. $L_{u x}$ for varying mean wind velocities in turbulent flow

\begin{tabular}{cc}
\hline \hline$U[\mathrm{~m} / \mathrm{s}]$ & $L_{u x}-[\mathrm{m}]$ \\
\hline 20 & 0.028 \\
25 & 0.031 \\
30 & 0.032 \\
35 & 0.037 \\
\hline
\end{tabular}




\section{Section model blockage correction}

A list of the tested ice shapes and their resulting wind-tunnel blockage during testing is presented in Table 4. The mean blockage is found by taking the mean diameter of the model, except for ice shape I, where the model was not tested for a large range of angles. Here the mean blockage is found by calculating the mean diameter perpendicular to the flow for the range of angles-of-attack tested.

The maximum blockage of each model is determined as the ratio between the maximum cable/ice diameter $D_{\max }=2 r+t_{\max }$ and the cross-sectional height of the tunnel.

Corrections on the measured drag coefficients are made to account for the effect of tunnel blockage. Dalton (1971) presented an improved correction based on an originally proposed correction by Allan and Vincenti (1944), so that

$$
C_{D}=C_{D}{ }^{\prime}\left(1-\frac{1}{4}\left(\frac{D}{h}\right)^{2}-\frac{1}{2} C_{D}{ }^{\prime}\left(\frac{D}{h}\right)\right)
$$

where $C_{D}{ }^{\prime}$ is the measured drag coefficients, $D$ is the cylinders diameter, $h$ is the height of the test section in the wind tunnel and $C_{D}$ is the corrected drag coefficient.

According to Dalton, the application of Eq. (2) is valid for drag coefficients obtained in wind tunnel tests on circular cylinders in free stream, as long as the blockage generated by the cylinder is less than $\sim 30 \%$. It is assumed that this can be applied herewith, even though the cylinders are not perfectly circular.

The blockage correction applied to the data presented in this paper is obtained by using the model diameter of $0.07 \mathrm{~m}$ together with Eq. (2). The blockage correction leads to a maximum drag coefficient correction of $4.9 \%$ in turbulent flow and $5.7 \%$ in smooth flow.

\section{Test series and results}

A series of 22 static wind tunnel tests and 17 dynamic wind tunnel tests were undertaken on cylinders with and without simulated ice accretions. The tests are described below.

\subsection{Static tests}

The complete static test series is outlined in Table 5. Is should be noted that the test velocity ranges were chosen so as to lie in the anticipated regions of galloping instability. The critical

Table 4. Ice shapes and associated blockage for the prescribed wind tunnel tests

\begin{tabular}{ccccc}
\hline \hline ice shape & $D_{\text {mean }}=\operatorname{mean}\left(D_{i}\right)$ & $D_{\max }=\max \left(D_{i}\right)$ & $\begin{array}{c}\text { mean blockage } \\
D_{\text {mean }} / H_{\text {section }}\end{array}$ & $\begin{array}{c}\text { max blockage } \\
D_{\text {max }} / H_{\text {section }}\end{array}$ \\
\hline I & $7.56 \mathrm{~cm}$ & $7.67 \mathrm{~cm}$ & $10.78 \%$ & $10.96 \%$ \\
II & $9.01 \mathrm{~cm}$ & $9.29 \mathrm{~cm}$ & $12.88 \%$ & $13.27 \%$ \\
III & $8.96 \mathrm{~cm}$ & $9.13 \mathrm{~cm}$ & $12.79 \%$ & $13.04 \%$ \\
IV & $7.07 \mathrm{~cm}$ & $7.22 \mathrm{~cm}$ & $10.10 \%$ & $10.31 \%$ \\
\hline
\end{tabular}


Table 5. Test series employing static rig

\begin{tabular}{cccccc}
\hline \hline ice shape & flow & $\begin{array}{c}\text { surface of simulated } \\
\text { ice accretion }\end{array}$ & $\begin{array}{c}\text { wind velocity } \\
{[\mathrm{m} / \mathrm{s}]}\end{array}$ & $\begin{array}{c}\text { wind angles } \\
\left.\text { of attack [ }{ }^{\circ}\right]\end{array}$ & $\begin{array}{c}\text { hysteresis check } \\
\text { at angles }\end{array}$ \\
\hline \multirow{2}{*}{ I } & Smooth & Rough & {$[22,27,31,36,41]$} & {$[0,10,20,30,40]$} & - \\
& Smooth & Smooth & {$[22,27,31,36,41]$} & {$[0,10,20,30,40]$} & - \\
& Smooth & Rough & {$[22,27,31,36,41]$} & {$[-90,-85, \ldots, 85,90]$} & {$[-90,-80, \ldots, 80,90]$} \\
II & Turbulent & Rough & {$[13,17,22,27]$} & {$[-90,-85, \ldots, 85,90]$} & {$[-90,-80, \ldots, 80,90]$} \\
& Smooth & Rough & {$[22,27,31,36,41]$} & {$[-90,-85, \ldots, 85,90]$} & {$[-90,-80, \ldots, 80,90]$} \\
III & Turbulent & Rough & {$[13,17,22,27]$} & {$[-90,-85, \ldots, 85,90]$} & {$[-90,-80, \ldots, 80,90]$} \\
& Smooth & Rough & {$[22,27,31,36,41]$} & {$[0,5, \ldots, 175,180]$} & - \\
IV & Turbulent & Rough & {$[13,17,22,27]$} & {$[0,5, \ldots, 175,180]$} & - \\
\hline
\end{tabular}

vortex-shedding velocity for the tested cylinders is below $1 \mathrm{~m} / \mathrm{sec}$.

The experiments consisted of Reynolds number tests (Fig. 9), roughness tests (Fig.10) and a series of force coefficients tests (Figs. 11-16). All of the figures, except Fig.10, show the resulting coefficients for smooth and turbulent flow in the top and bottom rows, respectively. Fig. 10 shows the effect of the change in surface roughness and will be discussed later. All aerodynamic force coefficients have been corrected according to the measured velocity profiles and for blockage.

\subsubsection{Reynolds number test}

A Reynolds number test was performed on a smooth reference circular cylinder. The smooth cylinder was tested under both laminar and turbulent flow. The results of these two Reynolds number tests are presented in Fig.9. It is seen that the critical Reynolds number range for the turbulent flow is obtained for much lower Reynolds numbers. From this, it can be inferred that for turbulent flow the critical Reynolds number range was included in the test program for all cylinders. For smooth flow, it can be seen that the aerodynamic drag coefficient of the smooth cylinder is more or less constant for the whole range of Reynolds numbers.

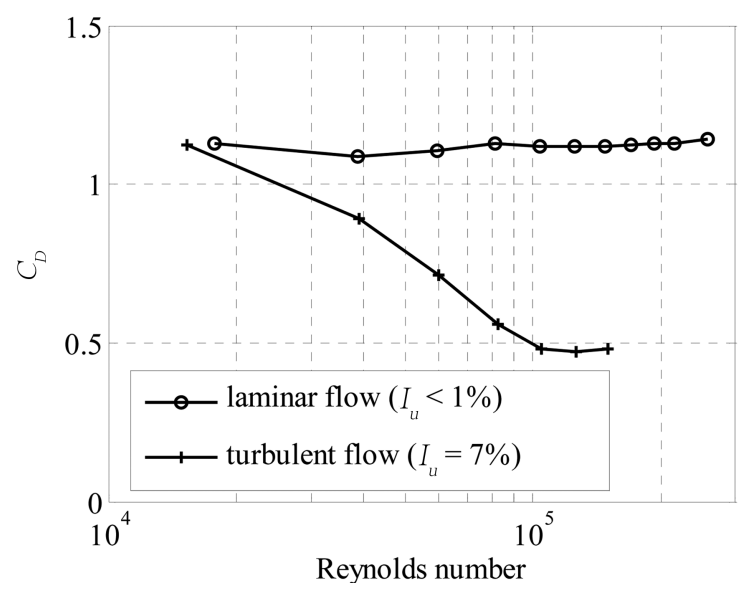

Fig. 9. Reynolds number tests in smooth and turbulent flow on a smooth reference circular cylinder 

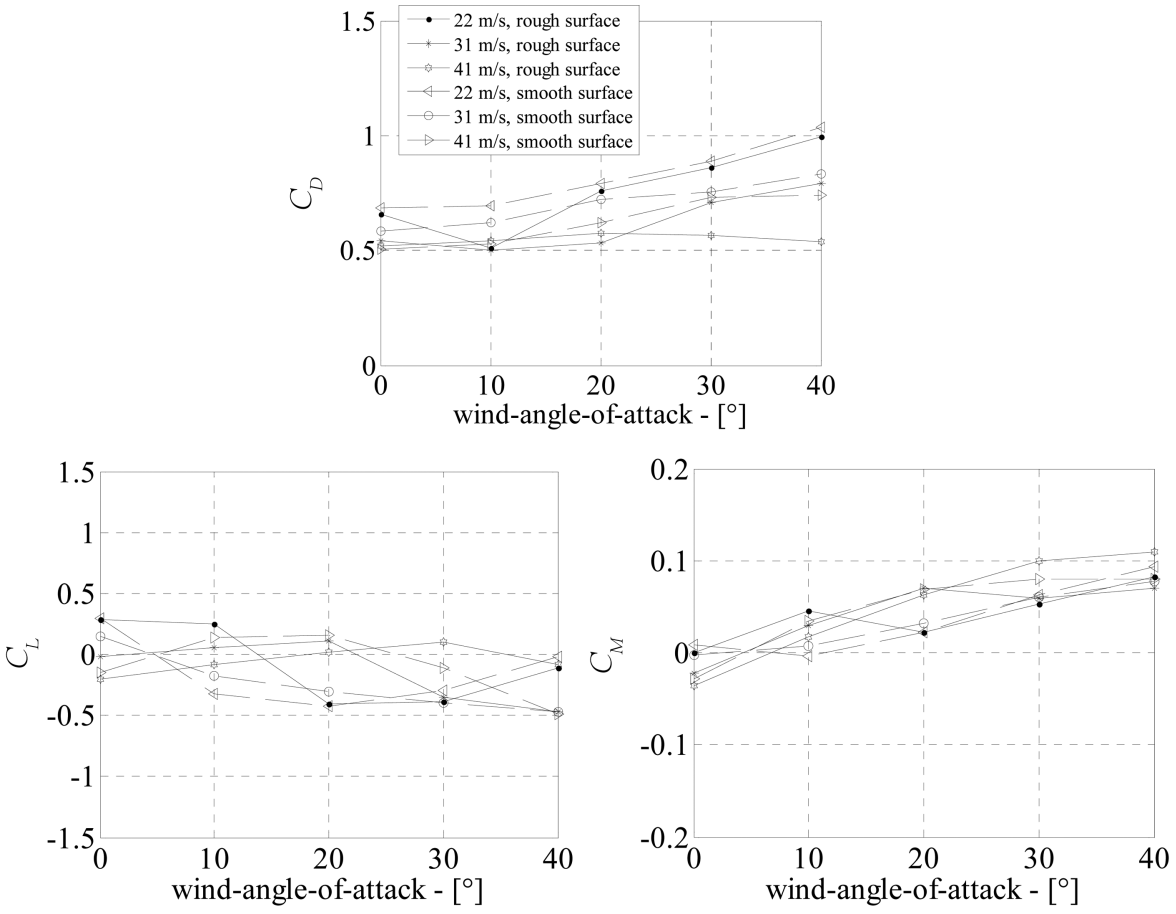

Fig. 10. Static force coefficients for ice shape I, with varying model surface roughness

\subsubsection{Surface roughness effect}

As the small series of Reynolds number tests indicated, Reynolds number effects can be observed when comparing the drag coefficients of smooth cylinders with and without turbulence. A series of tests were performed on ice shape I, in order to understand the effect of the surface roughness and the results are presented in Fig.10. Here, the rapidly prototyped model was first tested with the inherent surface roughness of the model after production. Then this was followed by a test where the model surface was coated with four layers of varnish to create a smooth surface. The tests show that the difference in drag and moment coefficients is small for most wind angles-of-attack - the exclusion being the drag coefficient for wind angle-of-attack of $10^{\circ}$ for $22 \mathrm{~m} / \mathrm{sec}$ wind velocity. No explanation can currently be provided for this. It should also be noted that the lift force is prone to large variations with changes in surface roughness.

The tests clearly demonstrate the effect of surface roughness on the force coefficients and show that, although dominant for the resulting flow field, cross-sectional shape is not the only parameter that affects the generated forces on an iced cylinder. In any case, as the roughness on an iced cylinder is not only difficult to measure, but also varies greatly from one condition to another, it was deemed adequate to use the aforementioned manufactured roughness from the rapid prototyping process.

\subsubsection{Force coefficients}

The force coefficients for ice shapes II and III are presented in Figs. 11 and 12. Once again, the same trend of greater Reynolds number dependency for turbulent flow is observed. For the drag coefficients, the Reynolds number dependency seems to follow the critical Reynolds number range 

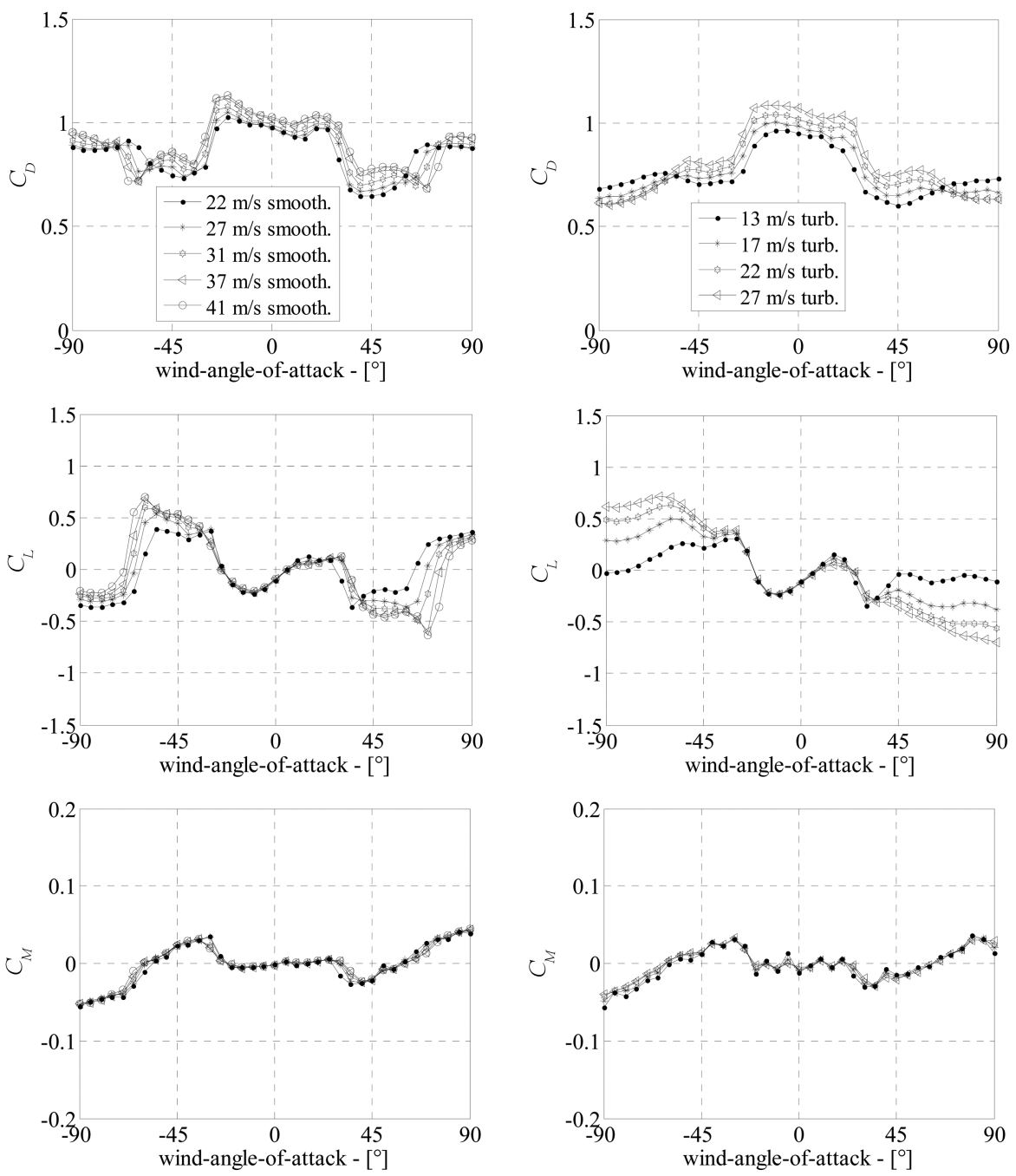

Fig. 11. Static force coefficients for ice shape II: smooth flow (left) and turbulent flow (right)

identified in Fig. 10. For the lift force coefficients, the Reynolds number dependency is concentrated in angles less than $-30^{\circ}$ and greater than $+30^{\circ}$, except for at narrow range close to the stagnation point $\left(0^{\circ}\right)$. No significant Reynolds number dependency is found for the moment coefficients.

For ice shape IV, the drag and lift coefficients (Fig. 13) generally exhibit Reynolds number dependency for both smooth and turbulent flow. The moment coefficients exhibit Reynolds number dependency for turbulent flow between wind angles-of-attack $10^{\circ}$ and $75^{\circ}$.

A closer examination of the drag and lift coefficients for ice shape IV reveals a dependency of the drag on the lift and vice-versa. A sudden drop or rise in the lift force is often accompanied by a sudden rise or drop in the drag. This may indicate a well-defined flow transition and/or a shift in the location of a flow separation bubble. Further work is needed to verify this.

Finally, an investigation for potential hysteresis in respect to wind velocity was undertaken. Hysteresis is defined here as a noticeable change to the force coefficients for a particular wind 

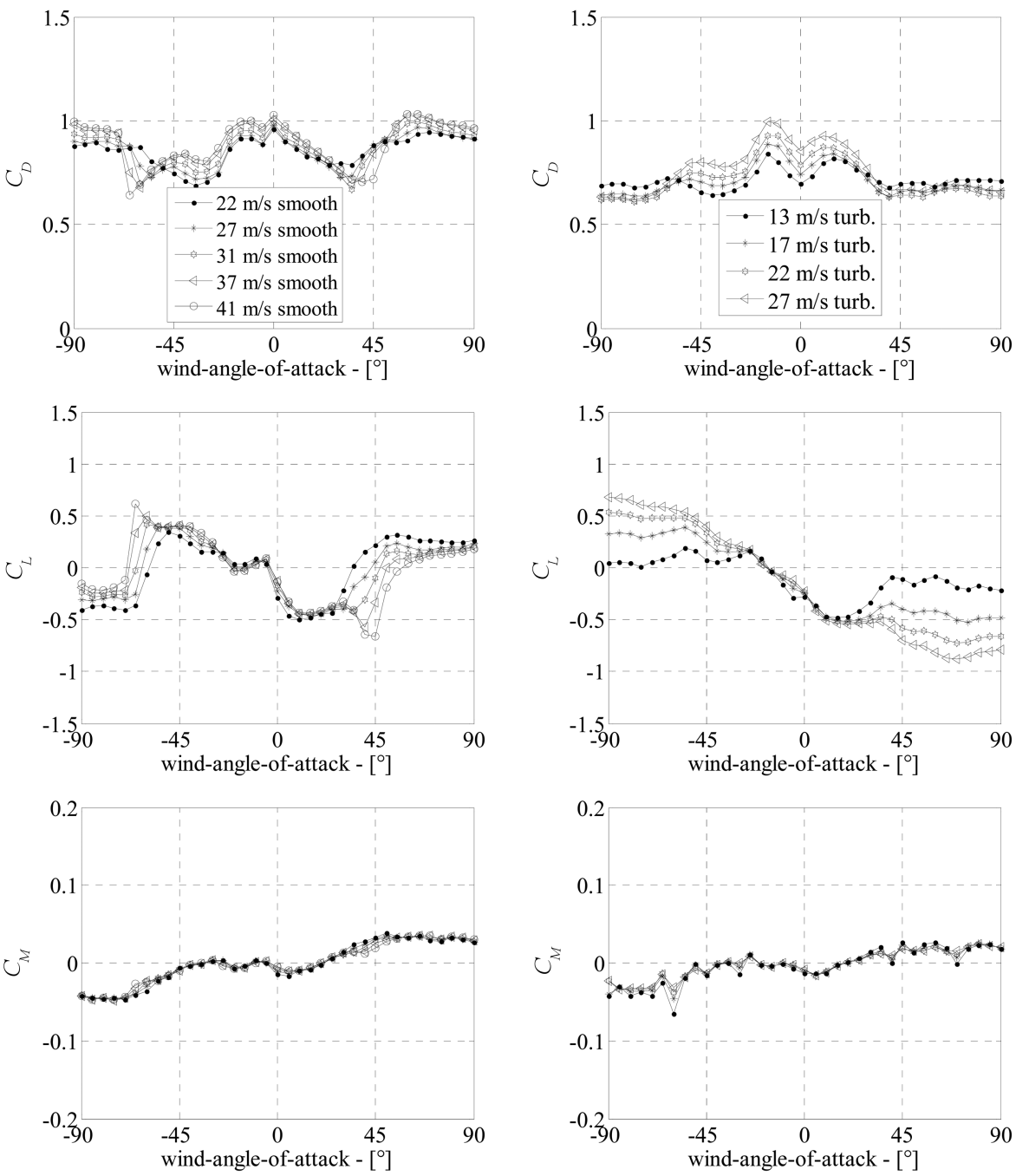

Fig. 12. Static force coefficients for ice shape III: smooth flow (left) and turbulent flow (right)

angle-of-attack and velocity when testing the model in the wind tunnel by rotating it in one direction and then rotating it back in the opposite direction for varying wind velocities. This was done for ice shapes II and III, for both smooth and turbulent flow by rotating the model forward by $5^{\circ}$ increments and back by $10^{\circ}$ increments. No significant hysteresis was observed.

\subsection{Dynamic tests}

The models with ice shapes that were tested dynamically were given the dynamic properties of an example cable, equivalent to a typical scaled suspension bridge hanger. Furthermore, the ice shapes used for the dynamic testing were chosen based on their similarity to those observed when large amplitude hanger vibrations were recorded on the Great Belt Suspension Bridge in Denmark (Gjelstrup et al. 2007). The ice shapes visually observed during this vibration event were very thin, 

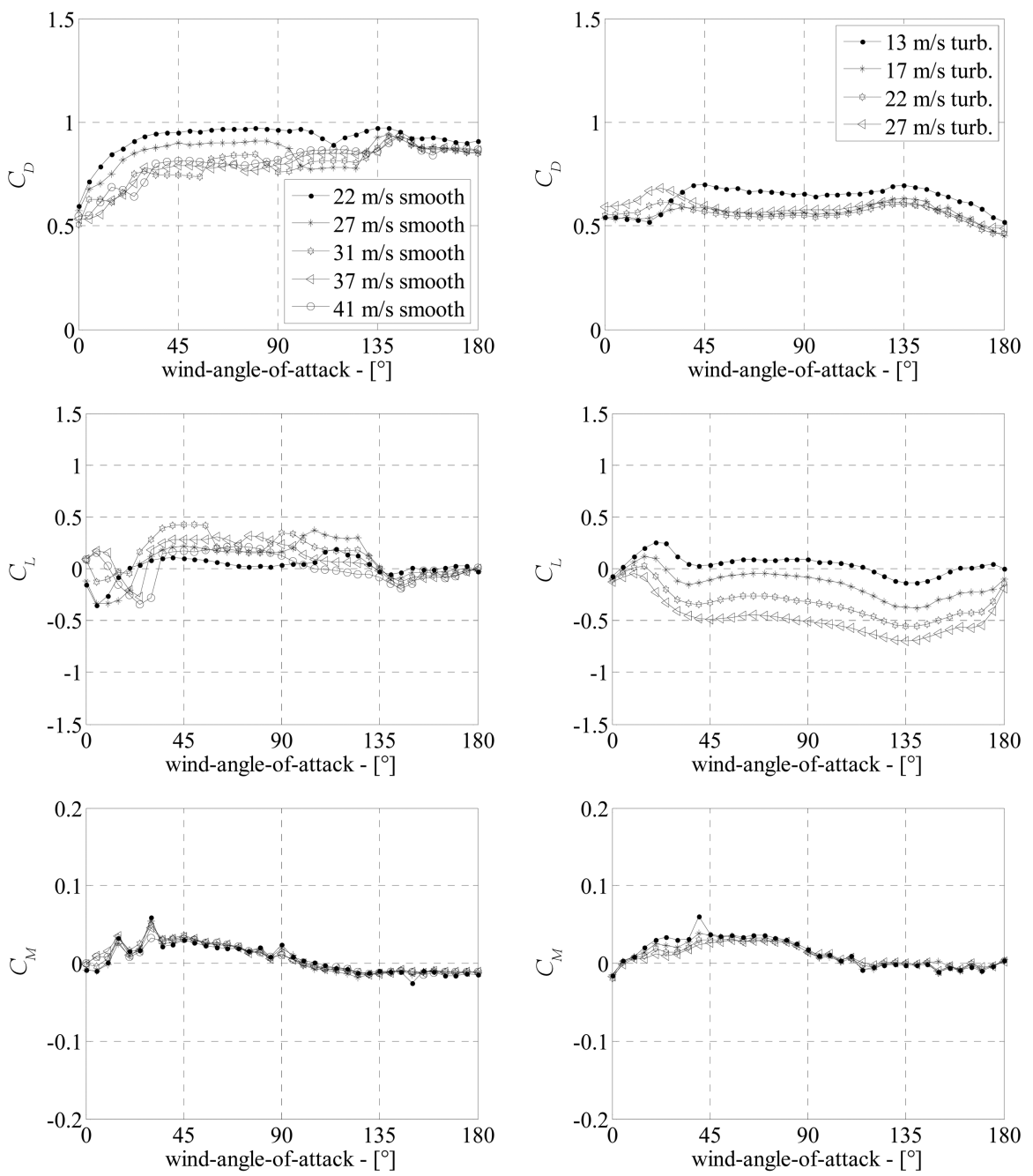

Fig. 13. Static force coefficients for ice shape IV: smooth flow (left) and turbulent flow (right)

with small protrusions of ice. Qualitatively, these are very similar to ice shapes II and III. Furthermore, the simulated ice shape IV was also chosen for ease of repeatability of future experiments. Finally, the reference cylinder was also tested.

Table 6 outlines the test series, whilst Table 7 presents the model parameters for the dynamic tests, namely vertical and torsional frequencies and damping, and the mass and mass moments of inertia.

The measured dynamic response for each ice shape is presented in Figs. 14-16. The results are presented as the non-dimensionalized standard deviation (STD) of the vertical displacement (top) and the STD of the angular rotation for pitch (axial rotation) (bottom). The results are presented for both smooth and turbulent flow. Plots for smooth flow are on the left, whilst plots for turbulent flow are placed to the right.

No instabilities were found in the experiments preformed on the reference cylinder. 
An evaluation of iced bridge hanger vibrations through wind tunnel testing and quasi-steady theory 399

Table 6. Dynamic test series

\begin{tabular}{cccccc}
\hline \hline ice shape & flow & $\begin{array}{c}\text { surface of } \\
\text { ice }\end{array}$ & $\begin{array}{c}\text { wind velocity } \\
{[\mathrm{m} / \mathrm{s}]}\end{array}$ & $\begin{array}{c}\text { angles } \\
{\left[{ }^{\circ}\right]}\end{array}$ & $\begin{array}{c}\text { hysteresis check } \\
\text { angles }\left[^{\circ}\right]\end{array}$ \\
\hline \multirow{2}{*}{ II } & smooth & rough & {$[22,27,31,36,41]$} & {$[90,85, \ldots,-85,-90]$} & {$[90,80, \ldots,-80,-90]$} \\
& turbulent & rough & {$[13,17,22,27]$} & {$[-90,-85, \ldots, 85,90]$} & {$[-90,-80, \ldots, 80,90]$} \\
\multirow{2}{*}{ III } & smooth & rough & {$[22,27,31,36,41]$} & {$[90,85, \ldots,-85,-90]$} & {$[90,80, \ldots,-80,-90]$} \\
& turbulent & rough & {$[13,17,22,27]$} & {$[-90,-85, \ldots, 85,90]$} & {$[-90,-80, \ldots, 80,90]$} \\
IV & smooth & rough & {$[22,27,31,36,41]$} & {$[0,5, \ldots, 175,180]$} & - \\
reference & turbulent & rough & {$[13,17,22,27]$} & {$[0,5, \ldots, 175,180]$} & - \\
\hline
\end{tabular}

Table 7. Model dynamic properties used for dynamic testing

\begin{tabular}{cccccc}
\hline \hline ice shape & vibration [direction] & freq [Hz] & damping [\% of crit.] & rig + model Mass [kg] & MMI [ $\left.\mathrm{kg} \cdot \mathrm{m}^{3} / \mathrm{m}\right]$ \\
\hline \multirow{2}{*}{ II } & vertical & 1.63 & 0.08 & 10.25 & 0.35 \\
& torsional & 4.99 & 0.43 & & \multirow{2}{*}{0.36} \\
III & vertical & 1.64 & 0.08 & 10.14 & \\
& torsional & 4.97 & 0.41 & 10.14 & 0.38 \\
IV & vertical & 1.64 & 0.07 & & 0.37 \\
& torsional & 4.99 & 0.56 & 10.01 & \\
V & vertical & 1.65 & 0.06 & & \\
& torsional & 4.99 & 0.51 & &
\end{tabular}
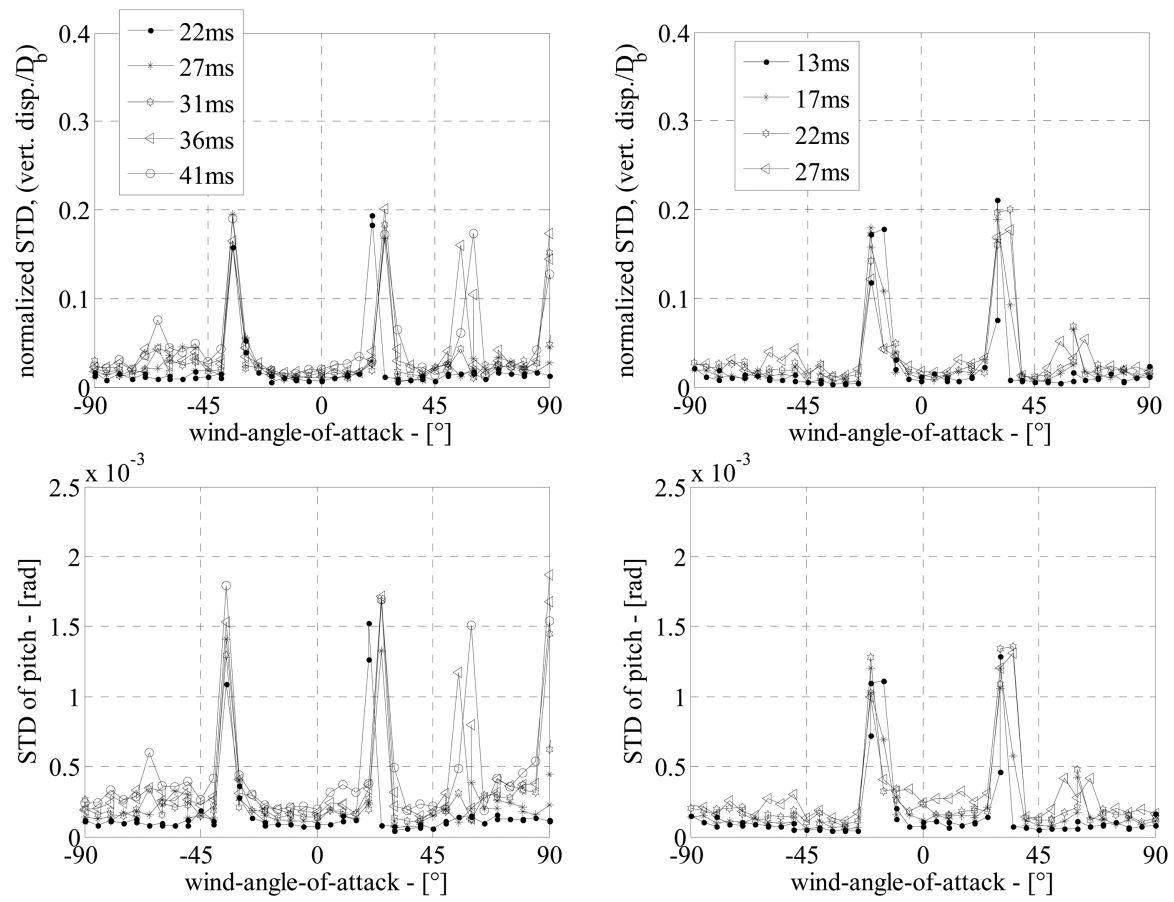

Fig. 14 Dynamic response for model with ice shape II. Non-dimensionalised STD of vertical displacement (top), STD of pitch in radians (bottom). Smooth flow (left) and turbulent flow (right) 

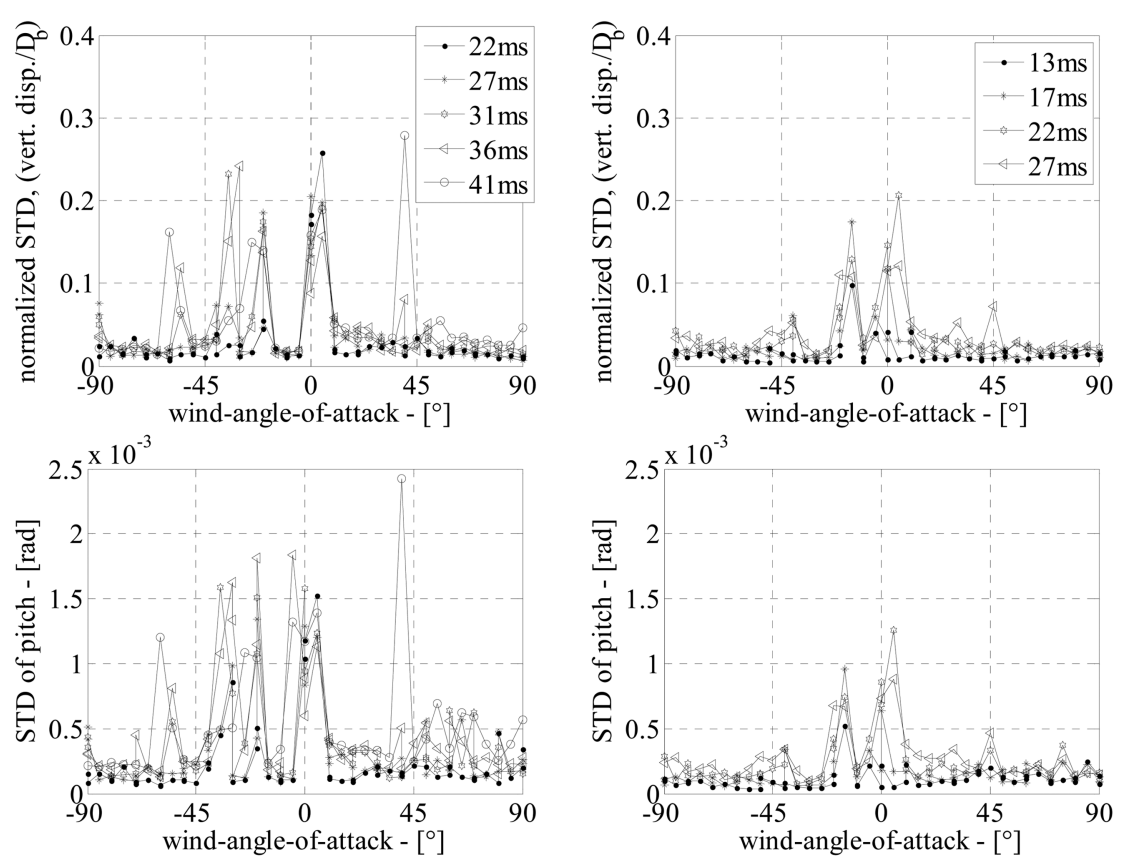

Fig. 15 Dynamic response for model with ice shape III. Non-dimensionalised STD of vertical displacement (top), STD of pitch in radians (bottom). Smooth flow (left) and turbulent flow (right)
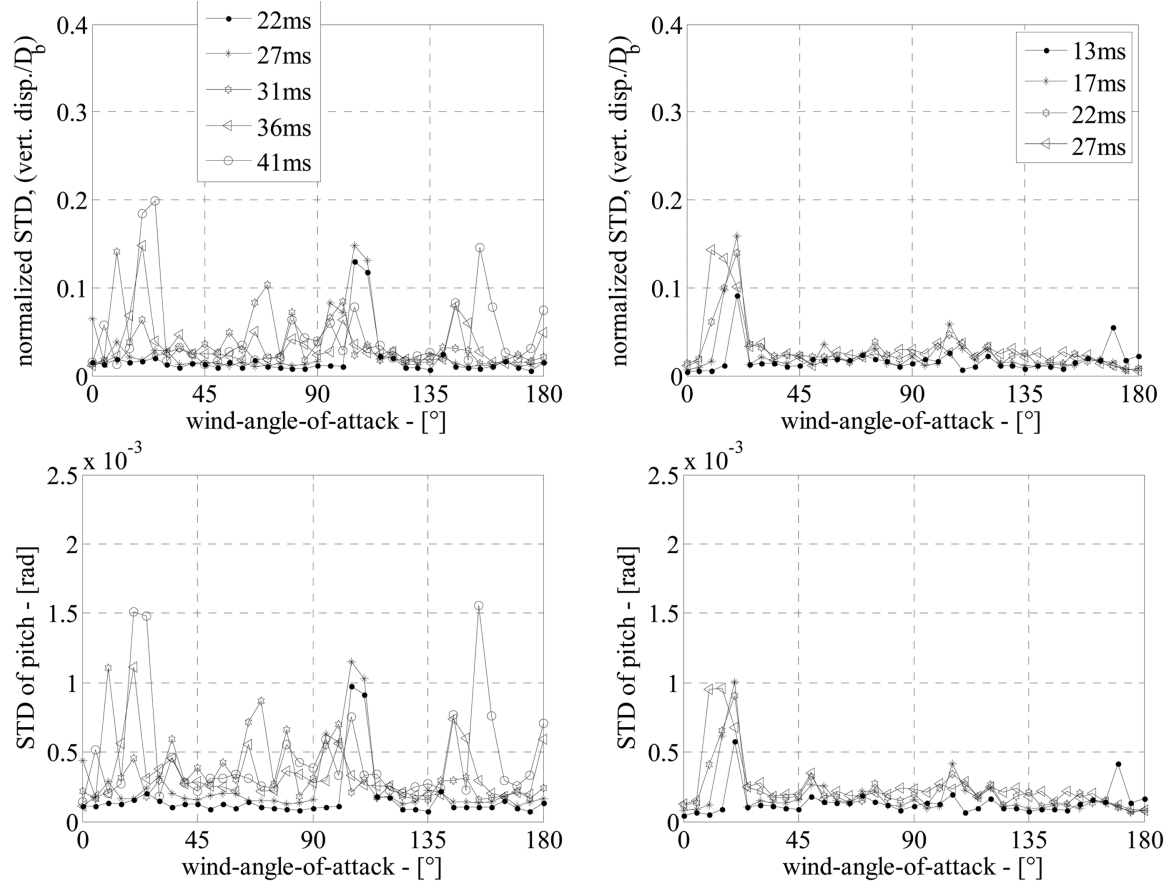

Fig. 16 Dynamic response for model with ice shape IV. Non-dimensionalised STD of vertical displacement (top), STD of pitch in radians (bottom). Smooth flow (left) and turbulent flow (right) 
For the purposes of analyzing the figures and for the development of instability plots, aerodynamic "instability" is defined as any normalized STD vertical displacement greater than 0.05 , i.e., $5 \%$ of the base cylinder diameter, as it was found that buffeting response dominates below this level.

For the turbulent flow tests, it can be seen that aerodynamic instability in the vertical direction occurs near the wind angle of attack at which the ice was formed. This is particularly true for ice shapes III and IV, where instability is observed exclusively in the range $\pm 20^{\circ}$. Instability for ice shape II in turbulent flow occurs within two intervals on each side of the stagnation point $\left(0^{\circ}\right)$, namely between $-25^{\circ}$ and $-10^{\circ}$, and between $25^{\circ}$ and $40^{\circ}$.

For the smooth flow tests, aerodynamic instability is generally more scattered. Instability occurs not only in the regions found for turbulent flow, but also for other wind angles-of-attack. Thus, the turbulent flow is shown to exhibit a stabilizing effect for certain angles.

Axial rotational instability, defined as a rotation greater than $0.5 \times 10^{-3} \mathrm{rad}$, seems to be coincident with vertical instability in most cases. However, it should also be noted that this rotation is relatively small and is most probably due to the offset between the cross-sectional center of mass and center of rotation.

\section{3-DOF quasi-steady model}

The static force coefficients obtained from the static tests were used for a galloping instability analysis employing quasi-steady theory. An adapted version of the 3-DOF quasi-steady model (accounting for the lack of horizontal translation) initially proposed by Gjelstrup and Georgakis (2011) and Gjelstrup et al. (2008) was used and is summarized herewith.

Fig. 17 shows a schematic model of a cylinder section with ice accretion. It is assumed that this is representative of an iced hanger section and the model is two-dimensional, with a section that is

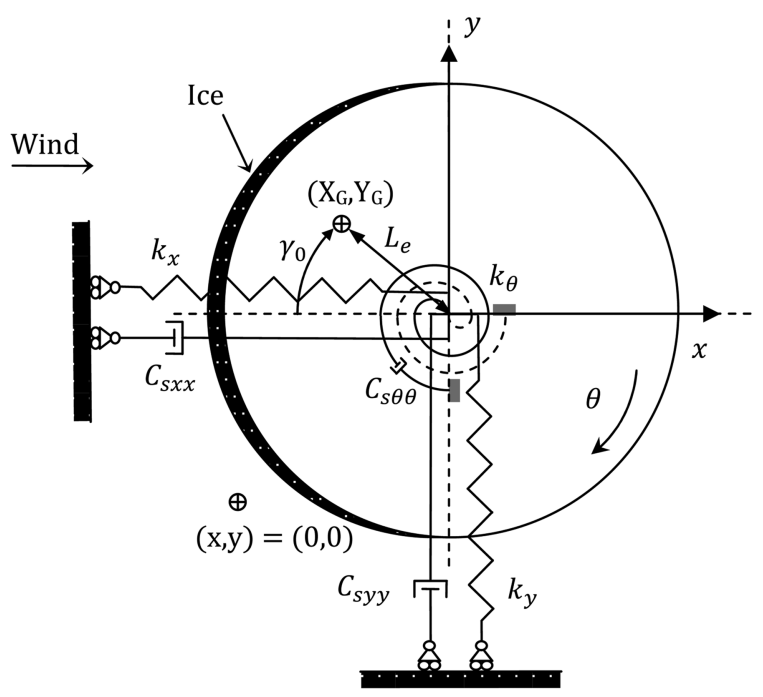

Fig. 17 Schematic model of cable section with ice accretion, $\left(X_{G}, Y_{G}\right)=$ mass centre. 
straight and rigid. The stiffness of the spring supports of the model is constant for all degrees-offreedom, i.e., stiffness does not change with respect to movement in $x$ and $y$ or rotation about the structural axis $(\theta)$. Also it is assumed that the structural damping force is proportional to velocity and that the wind velocity $U$ is constant. Furthermore it is assumed that the rotational velocity can be represented by a cross-sectionally dependant radial length times the radial rotational velocity, $\dot{\theta}$. Finally it is assumed that quasi-steady assumptions apply, that gravitational forces do not influence the model and that the cable is at rest at the initiation of any aerodynamic instability.

The equations of motion of the model presented in Fig. 23 can, per unit length, be written as

$$
\begin{aligned}
& m \ddot{x}+C_{s x x} \dot{x}+k_{x} x+m L_{e}\left(\cos (\varphi) \dot{\theta}^{2}+\sin (\varphi) \ddot{\theta}\right)=F_{x} \\
& m \ddot{y}+C_{s y y} \dot{y}+k_{y} y+m L_{e}\left(-\sin (\varphi) \dot{\theta}^{2}+\cos (\varphi) \ddot{\theta}\right)=F_{y} \\
& J \ddot{\theta}+C_{s \theta \theta} \dot{\theta}+k_{\theta} \theta+m L_{e}\left(\sin (\varphi) \ddot{x}+\cos (\varphi) \ddot{y}+L_{e} \ddot{\theta}\right)=F_{\theta}
\end{aligned}
$$

where the notation for time-dependant variables, $x(t), y(t)$ and $\theta(t)$, is represented as $x, y$ and $\theta$, respectively. Derivatives with respect to time are written as $(d / d t) x=\dot{x}$ and $\left(d^{2} / d t^{2}\right) x=\ddot{x} . m$ is the mass of the system and $J$ is the rotational inertia in relation to the mass centre $C_{s x x}$, is the structural damping in the x direction $C_{s y y}$, is the structural damping in the y direction, $C_{s \theta \theta}$, is the structural damping in the $\theta$ direction, $k_{x}, k_{y}$ and $k_{\theta}$ are the structural stiffnesses in the $\mathrm{x}, \mathrm{y}$ and $\theta$ directions, respectively, $L_{e}$ is the length to the centre of mass from the point of rotation, $\varphi=\gamma_{0}+\theta, \gamma_{0}$ is the angle offset for mass centre, $\theta$ is the structural rotation. $F_{x}, F_{y}$ and $F_{\theta}$ are the aerodynamic forces per unit length in the $x$ direction, $y$ direction and for torsion respectively, which are given by

$$
\begin{gathered}
F_{x}=\frac{1}{2} \rho U_{R}^{2} D\left(C_{D}\left(\alpha_{R}, R e_{R}\right) \cos \left(\alpha_{R}\right)+C_{L}\left(\alpha_{R}, R e_{R}\right) \sin \left(\alpha_{R}\right)\right) \\
F_{y}=\frac{1}{2} \rho U_{R}^{2} D\left(C_{L}\left(\alpha_{R}, R e_{R}\right) \cos \left(\alpha_{R}\right)-C_{D}\left(\alpha_{R}, R e_{R}\right) \sin \left(\alpha_{R}\right)\right) \\
F_{\theta}=\frac{1}{2} \rho U_{R}^{2} D^{2} C_{M}\left(\alpha_{R}, R e_{R}\right)
\end{gathered}
$$

where $\alpha_{R}=\left(\alpha_{0}+\theta+\beta\right), \alpha_{0}$ is the static wind-angle-of-attack, $\beta$ is the angle between static and relative wind directions, $R e_{R}$ is the relative Reynolds number, $\rho$ is the fluid density, $D$ is the characteristic width of a section model (the diameter for circular models), $C_{D}$ is the static drag coefficient, $C_{L}$ is the static lift coefficient and $C_{M}$ is the static moment coefficient. $U_{R}$ is the relative wind direction due to structural motion and rotation.

Again, following Gjelstrup and Georgakis (2011), the aerodynamic instability of the cable section is determined based on a linearization of the cable section's equations of motion (3)-(5) about the velocity $\dot{x}=\dot{y}=\dot{\theta}=0$. This linearization results in a dynamic force, which can be represented by the Jacobian damping matrix $\left(C_{a}\right)$ multiplied with the sectional velocity in the three directions, $\left(\boldsymbol{C}_{\boldsymbol{a}} \dot{\boldsymbol{Z}}\right)$ where $\dot{Z}=[\dot{x}, \dot{y}, \dot{\theta}]^{\prime}$ and 


$$
C_{a}=-\left[\begin{array}{lll}
\frac{\partial F_{x}}{\partial \dot{x}} & \frac{\partial F_{x}}{\partial \dot{y}} & \frac{\partial F_{x}}{\partial \dot{\theta}} \\
\frac{\partial F_{y}}{\partial \dot{x}} & \frac{\partial F_{y}}{\partial \dot{y}} & \frac{\partial F_{y}}{\partial \dot{\theta}} \\
\frac{\partial F_{\theta}}{\partial \dot{x}} & \frac{\partial F_{\theta}}{\partial \dot{y}} & \frac{\partial F_{\theta}}{\partial \dot{\theta}}
\end{array}\right]_{\dot{x}=\dot{y}=\dot{\theta}=0}
$$

With the aforementioned assumptions, the aerodynamic stability of the 3-DOF cable section can now be evaluated by rewriting Eqs. (3)-(5) into state space and solving the resulting eigenvalue problem.

The proposed 3-DOF quasi-steady galloping instability model can be used to generate 2dimensional plots of vertical aerodynamic instability in the parameter plane of wind angle-of-attack against wind velocity.

\section{Comparison of predicted and measured instability}

As ice shapes II-IV were tested dynamically, a comparison between the predicted and measured vertical aerodynamic instabilities is made. This comparison can be viewed in Figs. 18-20.
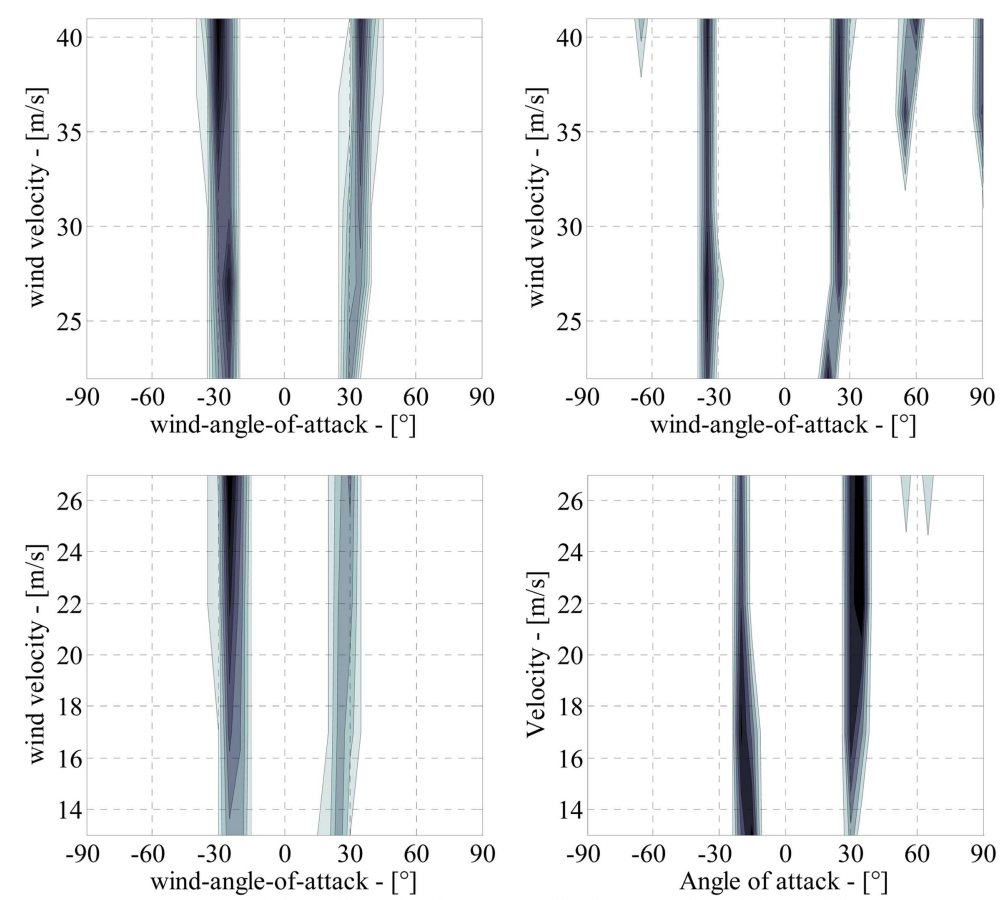

Fig. 18 Vertical aerodynamic instability for ice shape II as predicted from quasi-steady theory (left) and as determined from the dynamic tests (right). Smooth flow (top) and turbulent flow (bottom). Unstable regions are shaded. Darker regions qualitatively indicate increased level of damping needed to avoid instability 

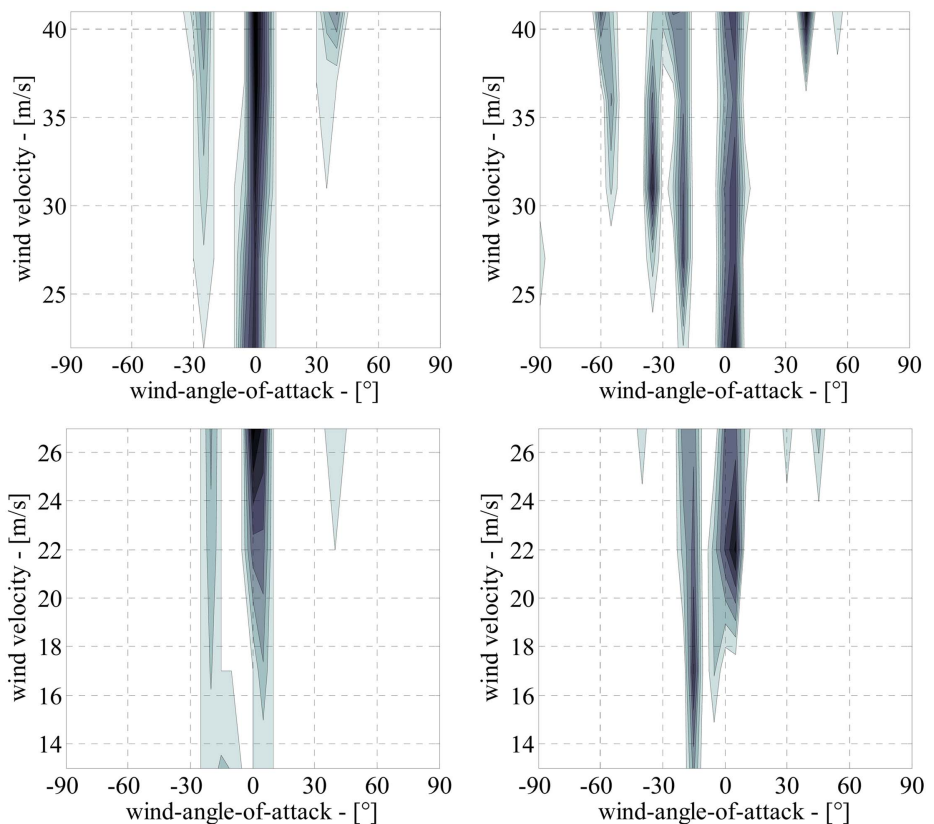

Fig. 19 Vertical aerodynamic instability for ice shape III as predicted from quasi-steady theory (left) and as determined from the dynamic tests (right). Smooth flow (top) and turbulent flow (bottom). Unstable regions are shaded. Darker regions qualitatively indicate increased level of damping needed to avoid instability
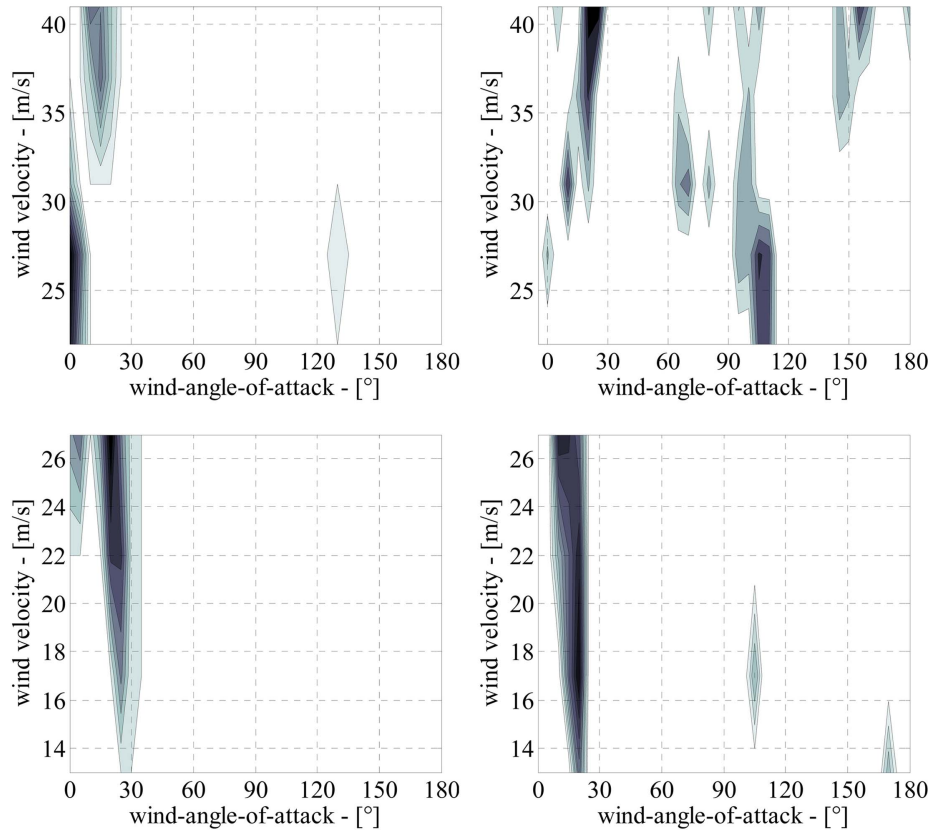

Fig. 20 Vertical aerodynamic instability for ice shape IV as predicted from quasi-steady theory (left) and as determined from the dynamic tests (right). Smooth flow (top) and turbulent flow (bottom). Unstable regions are shaded. Darker regions qualitatively indicate increased level of damping needed to avoid instability 
Generally, there is very good agreement between the predicted and measured aerodynamic instabilities, although some discrepancies can be evidenced. There are several potential reasons for this, including the small non-linearities in the dynamic test rig, the asymmetric flow conditions and the determination of the ice-accreted cylinder's cross-sectional radial length (Gjelstrup and Georgakis 2011).

\section{Conclusions}

It has been shown herewith that a thinly iced cylinder is prone to aerodynamic instability for specific wind angles-of-attack. Furthermore it has been found that only small changes in the wind angle of attack from the angle of attack from which the ice was formed, are necessary to induce this aerodynamic instability. This is an important observation, as it implies that only small changes in wind angle-of-attack are necessary to facilitate cylinder vibrations. This effect had been hypothesised by Gjelstrup et al. (2007) for suspension bridge hangers.

The static wind tunnel tests on (simulated) iced cylinders reveal the significant effect of ice on the static force coefficients of the cylinder. Utilizing example dynamic properties of a bridge hanger, together with the static force coefficients in an adapted 3-DOF quasi-steady instability model, produces regions of predicted vertical aerodynamic instability. These regions are predicted for both smooth and turbulent flow. Wind tunnel tests of the cylinders using a dynamic rig reveal actual regions of aerodynamic instability. When compared, it is shown that the 3-DOF quasi-steady model is capable of predicting the vertical aerodynamic instability observed from the dynamic wind tunnel tests.

\section{References}

AAllen, H.J. and Vincenti, W.G. (1944), Wall interference in a two-dimensional-flow wind tunnel, with consideration of the effect of compressibility, NACA, Rept.782.

Anderson, D.N., Hentschel, D.B. and Ruff, G.A. (1998), Measurement and correlation of ice accretion roughness, AIAA-98-0486.

Chabart, O. and Lilien, J.L. (1998), "Galloping of electrical lines in wind tunnel facilities", J. Wind Eng. Ind. Aerod., 74-76, 967-976.

Dalle, B. and Admirat, P. (2010), Wet snow accretion on overhead lines with French report of experience, Cold Regions Science and Technology. in press, corrected proof.

Dalton, C. (1971), "Allen and Vincenti blockage corrections in a wind tunnel”, AIAA J., 9(9), 1864-.1865.

ESDU (1986), Mean forces, pressures and flow field velocities for circular cylindrical structures: Single cylinder with two-dimensional flow, ESDU Item 80025, ESDU International, London, U.K.

Fo chi, W., Yue fan, D., Cheng rong, L., Yu zhen, L. and Yu qian, Z. (2009), "Icing simulation system for transmission line", High Voltage Eng., 35(9), 2313-2316.

Gjelstrup, H. and Georgakis, C. (2009), "Aerodynamic Instability of a cylinder with thin ice accretion", Proceedings of the ISCD 2009, Paris.

Gjelstrup, H. and Georgakis, C. (2011), "A quasi-steady 3 degree-of-freedom model for the determination of the onset of bluff body galloping instability", J. Fluid. Struct., 27(7), 1021-1034.

Gjelstrup, H., Georgakis, C. and Larsen, A. (2007), "A preliminary investigation of the hanger vibrations on the Great Belt East Bridge", Proceedings of the 7th International Symposium on Cable Dynamics, Vienna (Austria).

Gjelstrup, H., Larsen, A., Georgakis, C. and Koss, H. (2008), "A new general 3DOF quasi-steady aerodynamic instability model", Proceedings of the BBAA VI International Colloquium on: Bluff Bodies Aerodynamics \& 
Applications, Milan, Italy, July, 20-24

Gurung, C.B., Yamaguchi, H. and Yukino, T. (2002), "Identification of large amplitude wind-induced vibration of ice-accreted transmission lines based on field observed data", Eng. Struct., 24(2), 179-188.

Hack, R.K. (1981), A wind tunnel investigation of four conductor models with simulated ice deposits. National Aerospace laboratory NLR, The Netherlands, 6. July, NLR TR 81076 L

Hansman, R.J., Breuer, E.S., Hazan, D., Reehorst, A. and Vargas, M. (1993), Close-up analysis of aircraft ice accretion, 31st Aerospace Sciences Meeting \& Exhibit.(93-0029).

Jamaleddine, A., McClure, G., Rousselet, J. and Beauchemin, R. (1993), "Simulation of ice-shedding on electrical transmission lines using adina", Comput. Struct., 47(4-5), 523-536.

Koss, H., Gjelstrup, H. and Georgakis, C.T. (2012), "Experimental study of ice accretion on circular cylinders at moderate low temperatures", J. Wind Eng. Ind. Aerod., 104-106, 540-546.

Kudzys, A. (2006), "Safety of power transmission line structures under wind and ice storms", Eng. Struct., 28(5), 682-689.

Lozowski, E.P., Stallabrass, J.R. and Hearty, P.F. (1983a), "The icing of an unheated, nonrotating cylinder. I. A simulation model ", J. Appl. Meteorol. Clim., 22(12), 2053-2062.

Lozowski, E.P., Stallabrass, J.R. and Hearty, P.F. (1983b), "The icing of an unheated, nonrotating cylinder. II.

Icing wind tunnel experiments", J. Appl. Meteorol. Clim., 22(12), 2063-2074.

McComber, P. and Paradis, A. (1995), "Simulation of the galloping vibration of a 2-dimensional iced cable shape", T. Can. Soc. Mech. Eng., 9(2), 75-92.

Nigol, O. and Buchan, P.G. (1981), "Conductor galloping .1. Den Hartog mechanism”, IEEE T. Power Syst., 100(2), 699-707.

Nigol, O. and Clarke, G.J. (1974), "Conductor galloping and control based on torsional mechanism", IEEE T. Power Syst., 93(6), 1729-1729.

Nigol, O.B. and P. G. (1981), "Conductor galloping .2. Torsional mechanism”, IEEE T. Power Syst., 100(2), 708-720.

Phuc, P.V. (2005), "A wind tunnel study on unstady forces of ice accreted transmission lines", Proceedings of the BBAA V 5th International Colloquium on Bluff Body Aerodynamics and Applications, Ottawa, Canada, July 11-16, 2005.

Shimizu, M. (2005), "A wind tunnel study on aerodynamic characteristics of ice accreted transmission lines", Proceedings of the BBAA V, 5th International Colloquium on Bluff Body Aerodynamics and Applications, Ottawa, Canada, July 11-16, 2005.

Wang, F., Li, C., Lv, Y., Lv, F. and Du, Y. (2010), "Ice accretion on superhydrophobic aluminum surfaces under low-temperature conditions”, Cold Reg. Sci.Technol., 62(1), 29-33.

$J H$

Table A. Positions measured, starting from "Side 2" of the wind tunnel

\begin{tabular}{|c|c|c|c|c|c|c|c|c|c|c|c|c|c|c|}
\hline \multicolumn{15}{|c|}{ smooth flow } \\
\hline Point & 1 & 2 & 3 & 4 & 5 & 6 & 7 & 8 & 9 & 10 & 11 & 12 & 13 & 14 \\
\hline Position [mm] & 12 & 19 & 26 & 33 & 40 & 47 & 54 & 61 & 68 & 75 & 122 & 232 & 342 & 452 \\
\hline Point & 15 & 16 & 17 & 18 & 19 & 20 & 21 & 22 & 23 & 24 & 25 & 26 & 27 & 28 \\
\hline Position [mm] & 562 & 672 & 782 & 892 & 925 & 932 & 939 & 946 & 953 & 960 & 967 & 974 & 981 & 988 \\
\hline \multicolumn{15}{|c|}{ turbulent flow } \\
\hline Point & 1 & 2 & 3 & 4 & 5 & 6 & 7 & 8 & 9 & 10 & 11 & 12 & 13 & 14 \\
\hline Position [mm] & 9 & 16 & 23 & 30 & 37 & 44 & 51 & 58 & 63 & 72 & 116 & 226 & 336 & 667 \\
\hline Point & 15 & 16 & 17 & 18 & 19 & 20 & 21 & 22 & 23 & 24 & 25 & 26 & - & - \\
\hline Position [mm] & 777 & 887 & 931 & 938 & 945 & 952 & 959 & 966 & 973 & 980 & 987 & 994 & - & - \\
\hline
\end{tabular}


An evaluation of iced bridge hanger vibrations through wind tunnel testing and quasi-steady theory 407

\section{Appendix A: Velocity profiles}

Example plots of the found velocity profiles are shown below. The variation seen in the turbulent velocity profiles could be attributable to the location of the turbulence grid, due to the relatively short distance between the hotwire measurements and the grid.

\section{Smooth flow}
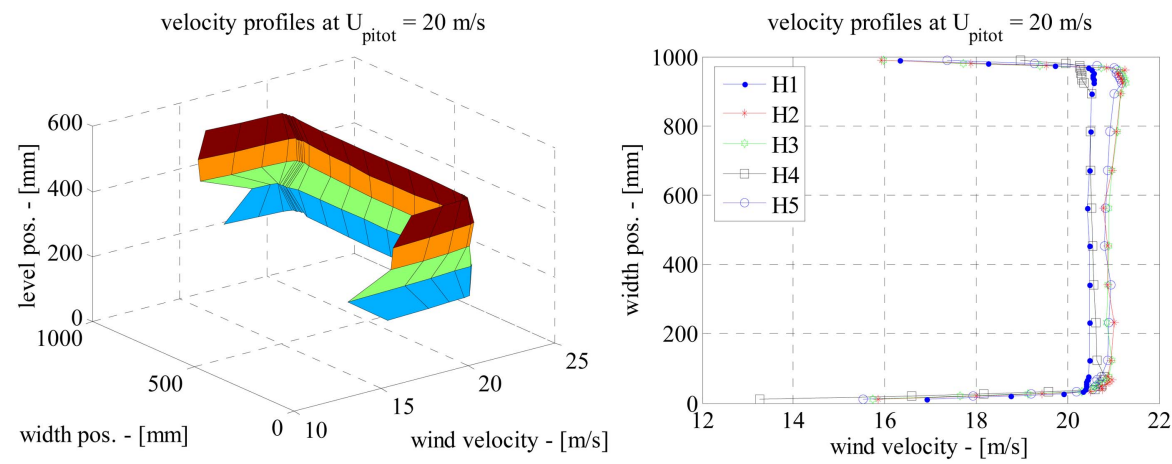

Turbulent flow
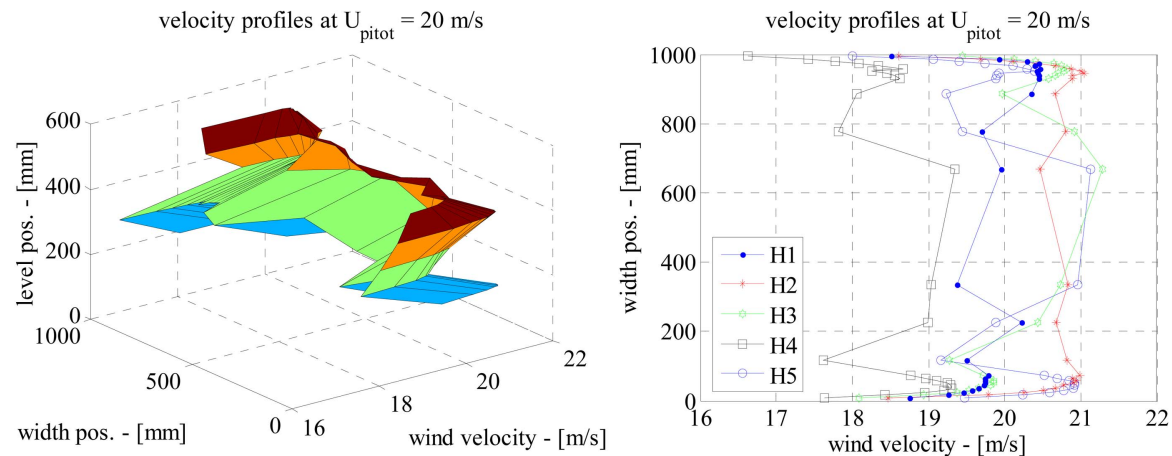